Erratum

\title{
Erratum: Luan, E.X.; Shoman, H.; Ratner, D.M.; Cheung, K.C.; Chrostowski, L. Silicon Photonic Biosensors Using Label-Free Detection. Sensors 2018, 18, 3519
}

\author{
Enxiao Luan ${ }^{1, *(\mathbb{D}}$, Hossam Shoman ${ }^{1}\left(\mathbb{D}\right.$, Daniel M. Ratner ${ }^{2}$, Karen C. Cheung ${ }^{1}$ \\ and Lukas Chrostowski ${ }^{1}$ \\ 1 Department of Electrical and Computer Engineering, University of British Columbia, 2329 West Mall, \\ Vancouver, BC V6T 1Z4, Canada; hoshoman@ece.ubc.ca (H.S.); kcheung@ece.ubc.ca (K.C.C.); \\ lukasc@ece.ubc.ca (L.C.) \\ 2 Department of Bioengineering, University of Washington, 3720 15th Ave. NE, Seattle, WA 98195-5061, USA; \\ dratner@uw.edu \\ * Correspondence: eluan@ece.ubc.ca; Tel.: +1-(604)822-8507
}

Received: 15 January 2019; Accepted: 16 January 2019; Published: 7 March 2019

The authors wish to make the following corrections in their published paper in Sensors [1].

In the last paragraph of page 8, the original article printed "Later, in 2010, Skivesen et al. achieved an improved DL of $6.75 \times 10^{-4}$ RIU by tracking sharp fringes appearing in the slow-light regime near the edge of the guided band." The last name of the first author and the detection limit value are incorrect. It should be revised as follows: "Later, in 2010, García-Rupérez et al. achieved an improved DL of $3.5 \times 10^{-6}$ RIU by tracking sharp fringes appearing in the slow-light regime near the edge of the guided band."

In the reference section, reference number 116 was incorrect. It was printed as "Joannopoulos, J.D.; Johnson, S.G.; Winn, J.N.; Meade, R.D. Photonic Crystals: Molding the Flow of Light; Princeton University Press: Princeton, NJ, USA, 2011." It should be revised as follows: "Popović, M. Theory and design of high-index-contrast microphotonic circuits. PhD Thesis, Massachusetts Institute of Technology, Cambridge, MA, USA, 2008."

Reference number 193 was incorrect. It was printed as “Martincek, I.; Kacik, D. A PDMS microfiber Mach-Zehnder interferometer and determination of nanometer displacements. Opt. Fiber Technol. 2018, 40, 13-17." It should be revised as follows: "Yoshida, S.; Ishihara, S.; Arakawa, T.; Kokubun, Y. Highly sensitive optical biosensor based on silicon-microring-resonator-loaded Mach-Zehnder interferometer. Jpn J. Appl. Phys. 2017, 56, 04CH08."

The authors would like to sincerely apologize for any inconvenience caused to the readers by these changes.

\section{Reference}

1. Luan, E.; Shoman, H.; Ratner, D.M.; Cheung, K.C.; Chrostowski, L. Silicon Photonic Biosensors Using Label-Free Detection. Sensors 2018, 18, 3519. [CrossRef] [PubMed]

(C) 2019 by the authors. Licensee MDPI, Basel, Switzerland. This article is an open access article distributed under the terms and conditions of the Creative Commons Attribution (CC BY) license (http:// creativecommons.org/licenses/by/4.0/). 